The Relationship between Egg Size and Chick Size in the Laughing Gull and Japanese Quail Author(s): Robert E. Ricklefs, D. Caldwell Hahn and William A. Montevecchi Source: The Auk, Vol. 95, No. 1 (Jan., 1978), pp. 135-144

Published by: University of California Press on behalf of the American Ornithologists' Union Stable URL: http://www.jstor.org/stable/4085504

Accessed: 27/06/2013 07:05

Your use of the JSTOR archive indicates your acceptance of the Terms \& Conditions of Use, available at http://www.jstor.org/page/info/about/policies/terms.jsp

JSTOR is a not-for-profit service that helps scholars, researchers, and students discover, use, and build upon a wide range of content in a trusted digital archive. We use information technology and tools to increase productivity and facilitate new forms of scholarship. For more information about JSTOR, please contact support@jstor.org. 


\title{
THE RELATIONSHIP BETWEEN EGG SIZE AND CHICK SIZE IN THE LAUGHING GULL AND JAPANESE QUAIL
}

\author{
Robert E. Ricklefs, D. Caldwell Hahn, and William A. Montevecchi
}

\begin{abstract}
Variation in the water, lipid, and nonlipid dry matter of eggs and newly hatched chicks of the Laughing Gull and Japanese Quail was related to variation in the size of the egg. Egg contents of the two species were, on average, very similar. Yolk size varied in direct proportion to egg size, but in the quail large eggs contained disproportionately low levels of lipid and high levels of nonlipid dry matter.

The composition of the newly hatched gull chick closely resembled that of the newly hatched quail. With increasing egg size, and thus chick size, water level increased and lipid level decreased in the gull chick, whereas lipid level increased in the quail chick. Among body organs, the integument of the gull exhibited a disproportionate increase with an increase in egg size, owing mostly to the accumulation of water; in the quail, the legs were the only organs to increase out of proportion to increase in body size. Disproportionate decreases in body proportion with increasing chick size appeared mostly in the head, stomach, and intestine components of both species.

Variation in proportions of lipid and water in the chick related to egg size is discussed in terms of (1) ecological requirements of newly hatched chicks, (2) sibling competition within broods, and (3) stage of development of the young at hatching.-Department of Biology, University of Pennsylvania, Philadelphia, Pennsylvania 19174 (first author); and Institute of Animal Behavior, Rutgers University, Newark, New Jersey 07102. Accepted 19 August 1976.
\end{abstract}

POULTRY scientists have known for more than 50 years that, in the domestic fowl, large eggs produce large chicks (Halbersleben and Mussehl 1922). Chick size has also been related to characteristics of post-hatching development and survival (Upp 1928, Wiley 1950, Skogland et al. 1952). More recent studies on nondomesticated species are beginning to reveal similar relationships (Parsons 1970, Schifferli 1973, Davis 1975), but we do not yet fully understand the significance of variation in egg size in natural populations.

In some species of gulls and terns, the last egg of the clutch is smaller than the first two (Paludan 1951, Preston and Preston 1953, Behle and Goates 1957, Coulson 1963, Harris 1964, Parsons 1970, Nisbet 1973). Conversely, in the Crested Penguin (Eudyptes pachyrhynchus) the second egg of the 2-egg clutch is $20 \%$ larger than the first (Warham 1974). Most species, however, show little consistent variation in egg size within a clutch (e.g. Kendeigh et al. 1956), and most intrapopulation variation in egg size occurs between, rather than within, clutches. Nevertheless in at least one passerine, the Great Tit (Parus major), egg size and growth rate are related (Schifferli 1973).

The survival advantage of chicks from large eggs presumably derives from either large body size, large yolk reserves, or both. These characteristics must reflect in turn systematic relationships between the size and contents of freshly laid eggs (Parsons 1970). This study was initiated to determine the relationships between egg size, egg composition, and chick composition in two precocial species: the Laughing Gull (Larus atricilla) and the Japanese Quail (Coturnix coturnix japonica). Eggs and chicks from eggs of known size were analyzed for lipid, water, and nonlipid dry matter content and for the distribution of these constituents among various body components at hatching. 
TABLE 1

Variation in the Size of Eggs and Chicks of the Laughing Gull and Japanese QuaIl

\begin{tabular}{|c|c|c|c|c|c|}
\hline & \multirow{2}{*}{$\begin{array}{c}\text { Sample } \\
\text { size }\end{array}$} & \multicolumn{4}{|c|}{ Wet weight (g) } \\
\hline & & Mean & SD & $\mathrm{CV}^{1}$ & Range \\
\hline \multicolumn{6}{|l|}{ Laughing Gull } \\
\hline Whole eggs ${ }^{2}$ & 9 & 42.08 & 3.87 & 9.2 & $36.7-49.0$ \\
\hline Whole eggs ${ }^{3}$ & 17 & 43.45 & 2.97 & 6.8 & $36.3-48.2$ \\
\hline \multicolumn{6}{|l|}{ Chicks } \\
\hline preprocessing $^{4}$ & 17 & 28.77 & 3.40 & 11.8 & $23.1-34.1$ \\
\hline postprocessing ${ }^{4}$ & 17 & 27.81 & 3.21 & 11.9 & $22.6-32.7$ \\
\hline minus yolk & 17 & 23.89 & 3.20 & 13.4 & $19.3-28.7$ \\
\hline yolk only & 17 & 3.91 & 1.08 & 27.6 & $1.9-6.3$ \\
\hline \multicolumn{6}{|l|}{ Japanese Quail } \\
\hline Whole eggs ${ }^{2}$ & 15 & 10.05 & 0.88 & 8.8 & $7.8-11.1$ \\
\hline Whole eggs $^{3}$ & 8 & 9.50 & 0.93 & 9.8 & $8.6-10.9$ \\
\hline \multicolumn{6}{|l|}{ Chicks } \\
\hline preprocessing $^{4}$ & 8 & 6.50 & 0.89 & 13.7 & $5.1-8.1$ \\
\hline postprocessing ${ }^{4}$ & 8 & 6.27 & 0.86 & 13.8 & $5.0-7.8$ \\
\hline minus yolk & 8 & 5.83 & 0.71 & 12.2 & $4.5-6.9$ \\
\hline yolk only & 8 & 0.44 & 0.25 & 57.7 & $0.2-1.0$ \\
\hline
\end{tabular}

${ }^{1}$ Standard deviation expressed as a percentage of the mean

2 Sample used to analyze egg contents.

3 Sample used to analyze chicks.

${ }^{4}$ Preprocessing refers to weight prior to dissection; postprocessing refers to sum of component weights after dissection; difference is the processing loss.

\section{Materials AND MethodS}

Quail eggs were obtained from Truslow Farms in Chesterton, Maryland; gull eggs were collected at the Rutgers University Institute of Animal Behavior Field Station at Brigantine, New Jersey. Eggs were incubated at $37^{\circ} \mathrm{C}$. During the hatching period, eggs were checked frequently enough to assure that chicks did not hatch more than 3 hours prior to collection. Chicks were killed by thoracic compression and were frozen for up to one week before they were processed. Eggs were processed in fresh condition. Samples were dried to constant weight in an oven at $80^{\circ} \mathrm{C}$ (about 24 hours). Lipids were extracted in a mixture of petroleum ether and chloroform (Ricklefs 1975). Chicks were dissected into 11 components (integument, legs, wings, pectoral muscles, head, heart, liver, stomach, intestines, body carcass, and yolk sac (see Ricklefs 1975)) before they were processed.

\section{RESULTS}

Variation in egg size and composition.-The standard deviation (SD) in egg weight of the Laughing Gull was about 4 times that of the Japanese Quail, but because gull eggs weigh about 4 times as much as quail eggs the relative degree of variation was similar in the 2 species (Table 1). Coefficients of variation (SD $\times 100 / \overline{\mathbf{x}}$ ) were $7-10 \%$ in the samples of eggs analyzed in this study. Samples of eggs used for analysis of egg contents and those incubated for subsequent analysis of chicks did not differ significantly $(\boldsymbol{P}>0.05)$ in mean or variance.

In the Laughing Gull egg weight decreased with the order of laying. Mean fresh weights and standard deviations for 9 clutches used in this study were: First, 44.8 $\mathrm{g} \pm 2.7$; second, $42.8 \mathrm{~g} \pm 3.4$, third, $40.6 \mathrm{~g} \pm 4.0$; all eggs combined, $42.7 \mathrm{~g} \pm 3.7$. The weights of third eggs averaged $90.6 \%$ of first eggs. In other studies, this percentage varied from $88.9 \%$ for the Herring Gull (Larus argentatus) to $94.3 \%$ for the Lesser Black-backed Gull (Larus fuscus), $98.0 \%$ for the Greater Black-backed Gull (L. marinus) (Harris 1964), 90.6\% for the Lesser Black-backed Gull (Paludan 1951), and $93.0 \%$ for the Laughing Gull (Preston and Preston 1953).

An analysis of variance indicated that in the sample of Laughing Gull eggs in this study (9 clutches of 3 ), position within the clutch accounted for $21.7 \%$ of the varia- 
TABLE 2

Relationship of Egg Components to Egg Weight in the LaUghing Gull and JaPanese Quail ${ }^{1}$

\begin{tabular}{lcc}
\hline \hline \multicolumn{1}{c}{ Component } & Correlation coefficient & Slope of regression ${ }^{2}$ \\
\hline Yolk & & \\
Laughing Gull & 0.81 & 0.31 \\
Japanese Quail & 0.91 & 0.31 \\
Percent yolk in egg & & \\
Laughing Gull & -0.05 & $\mathrm{NS}$ \\
Japanese Quail & -0.01 & $\mathrm{NS}$ \\
Percent lipid in yolk & & $\mathrm{NS}$ \\
Laughing Gull & -0.29 & -1.12 \\
Japanese Quail & -0.59 & \\
Percent albumen in egg & & $\mathrm{NS}$ \\
Lauging Gull & 0.16 & 1.03 \\
Japanese Quail & 0.53 & \\
Percent water in albumen & & $\mathrm{NS}$ \\
Laughing Gull & -0.19 & -0.35 \\
Japanese Quail & -0.54 & \\
\hline
\end{tabular}

${ }^{1}$ Regression statistics are presented for the relationships between the components listed and fresh egg weight. Units for slopes are $g / g$ egg weight (yolk) and \%/g egg weight.

Slopes are given only for significant correlations; NS = slope not significantly different from 0.

tion within the sample as a whole. An $F$-test for significance of heterogeneity of egg weight gave a probability close to $0.95(F=3.33)$ that differences between egg weights related to order of laying were not the result of random variation. We had no comparable information on laying sequence for the quail eggs.

Gull and quail eggs resembled each other closely in average composition, reflecting the similarity of the chicks at hatching (Ricklefs 1977a). Of the wet weight of the egg, yolk comprised $31.3 \%$ in the quail and $33.2 \%$ in the gull; albumen, $54.4 \%$ and $57.7 \%$; dried shell, $7.5 \%$ and $6.3 \%$. The water content of the albumen was nearly identical in the two species: $87.6 \%$ in the quail and $87.5 \%$ in the gull. The yolk of the quail contained slightly less water (48.6\%) and more nonlipid dry matter $(20.3 \%)$ than that of the gull 54.5 and $16.5 \%$ ). For the egg as a whole, water, lipid, and nonlipid dry constituents, ratio of yolk to albumen, and energy content ( $\mathrm{kcal} / \mathrm{g}$ fresh weight) were nearly identical (Ricklefs 1974, 1977a).

In both the quail and the gull the size of the yolk varied in direct proportion to the size of the egg (Table 2). As egg size increased in the quail, the proportion of albumen

TABLE 3

Average Composition of Newly Hatched Chicks and Relationship Between Composition and EgG Size in the LaUghing Gull aNd Japanese QuaIl ${ }^{1}$

\begin{tabular}{|c|c|c|c|c|c|c|c|c|}
\hline & \multicolumn{2}{|c|}{ Wet weight } & \multicolumn{2}{|c|}{ Water } & \multicolumn{2}{|c|}{ Nonlipid dry matter } & \multicolumn{2}{|c|}{ Lipid } \\
\hline & $\overline{\mathbf{x}}$ & b & $\overline{\mathbf{x}}$ & b & $\overline{\mathbf{x}}$ & b & $\overline{\mathbf{x}}$ & b \\
\hline \multicolumn{9}{|c|}{ Laughing Gull } \\
\hline $\begin{array}{l}\text { Chick } \\
\text { Yolk } \\
\text { Total }\end{array}$ & $\begin{array}{r}551 \\
90 \\
641\end{array}$ & $\begin{array}{l}750^{* *} \\
167 * \\
917 * * *\end{array}$ & $\begin{array}{r}432 \\
49 \\
482\end{array}$ & $\begin{array}{l}681^{* *} \\
108^{*} \\
790^{* * *}\end{array}$ & $\begin{array}{r}94 \\
25 \\
119\end{array}$ & $\begin{array}{c}81^{*} \\
41 \\
122^{* * *}\end{array}$ & $\begin{array}{l}25 \\
16 \\
41\end{array}$ & $\begin{array}{r}-13 \\
18 \\
5\end{array}$ \\
\hline \multicolumn{9}{|c|}{ Japanese Quail } \\
\hline $\begin{array}{l}\text { Chick } \\
\text { Yolk } \\
\text { Total }\end{array}$ & $\begin{array}{r}613 \\
46 \\
660\end{array}$ & $\begin{array}{c}704 * \\
89 \\
792 *\end{array}$ & $\begin{array}{r}466 \\
30 \\
496\end{array}$ & $\begin{array}{c}527 * \\
56 \\
582 *\end{array}$ & $\begin{array}{r}108 \\
9 \\
117\end{array}$ & $\begin{array}{c}115^{*} \\
21 \\
135^{* *}\end{array}$ & $\begin{array}{r}39 \\
8 \\
47\end{array}$ & $\begin{array}{l}62 * \\
13 \\
75^{*}\end{array}$ \\
\hline
\end{tabular}

${ }^{1}$ Mean weight $(\bar{x})$ expressed in milligrams per gram fresh egg weight. Slopes of regressions between components and fresh egg weight (b) expressed in $\mathrm{mg} / \mathrm{g}$ fresh egg weight. Significance of correlations: $* P<0.05 ; * * P<0.01 ; * * * P<0.001$. 
TABLE 4

Statistical ANalysis of Differences between Coefficients of Variation in Egg and Chick Weights of The LaUghing Gull and Japanese QuaIL

\begin{tabular}{lcccc}
\hline \hline Comparison & Sample sizes & $\mathrm{CV}^{2}$ & $F$-ratio & $P$ \\
\hline Egg weight (egg sample) & & & & \\
\hline Egg weight (chick sample) & & & & \\
$\quad$ Laughing Gull & $9 / 17$ & $846 / 462$ & 1.83 & $>0.10$ \\
Japanese Quail & $15 / 8$ & $774 / 960$ & 1.24 & $>0.25$ \\
Egg weight (chick sample) & & & & \\
\hline$\quad$ Chick weight & & & & \\
Laughing Gull & $17 / 17$ & $462 / 1,392$ & 3.01 & $>0.025$ \\
Japanese Quail & $8 / 8$ & $960 / 1,876$ & 1.96 & $>0.10$ \\
Laughing Gull & & & & \\
Japanese Quail & & & & \\
$\quad$ Egg weight (chick sample) & $9 / 15$ & $846 / 774$ & 1.09 & $>0.25$ \\
Chick weight & $17 / 8$ & $1,392 / 1,876$ & 1.35 & $>0.25$ \\
\hline
\end{tabular}

in the egg increased slightly while the proportion of lipid in the yolk and proportion of water in the albumen decreased slightly. Composition of yolk and albumen in gull eggs did not vary with respect to egg size.

Variation in chick size.-The weight of the newly hatched chick (including yolk sac) averaged $66.0 \%$ of the weight of the fresh egg in the quail and $64.1 \%$ in the gull. In both species the body weight of the chick varied in accordance with the fresh weight of the egg from which it hatched (Table 3), but the absolute weight variation between chicks increased slightly over variation between eggs in the gull and decreased slightly in the quail (Table 1). The coefficient of variation in chick weight was $11.9 \%$ in the gull (compared to $6.8 \% \mathrm{CV}$ for egg weight) and $13.8 \%$ in the quail ( $9.8 \%$ for egg weight). Coefficients of variation differed statistically ( $F$-test based on the square of the coefficient of variation (Lewontin 1966)) only between egg size and chick size in the gull (Table 4).

Newly hatched Laughing Gull chicks had relatively larger yolks (18.2\% of body weight) than Japanese Quail chicks (11.2\%). The yolk reserves of the gull also contained higher levels of nonlipid dry matter $(28 \%$ vs. $20 \%)$ and lower levels of water (54\% vs. $65 \%)$, but similar levels of lipid (18\% vs. $17 \%)$. In both the quail and the gull yolk size increased relatively more rapidly than body size with an increase in

TABLE 5

Relationships of Relative Proportions of Body Components of Newly Hatched Chicks IN THE LaUghing Gull and JaPanese QuaIL

\begin{tabular}{llc}
\hline \hline & \multicolumn{2}{c}{ Slope of regression $^{1}$} \\
\cline { 2 - 3 } & Water index & Lipid index \\
\hline Laughing Gull & $0.077^{* *}$ & $-0.008^{*}$ \\
Chick & 0.021 & -0.008 \\
Yolk & $0.057^{*}$ & -0.007 \\
Total & & \\
Japanese Quail & 0.026 & 0.018 \\
Chick & 0.030 & -0.014 \\
Yolk & 0.010 & 0.016 \\
Total &
\end{tabular}

${ }^{1}$ Probability that slope is not statistically different from zero. ${ }^{*} P<0.05,{ }^{* *} P<0.01$. 
TABLE 6

Relationships of Relative Proportions of Body Components of Newly Hatched Chicks to Fresh Egg Weight in the Laughing Gull aNd JaPanese QuaIl

\begin{tabular}{lcc}
\hline \hline & \multicolumn{2}{c}{ Slope of regression $^{1}$} \\
\cline { 2 - 3 } Component & Laughing Gull & Japanese Quail \\
\hline Integument & $0.39^{* *}$ & 0.14 \\
Body & 0.12 & 0.63 \\
Intestines & -0.12 & -0.39 \\
Heart & $-0.04^{*}$ & 0.12 \\
Liver & -0.04 & 0.02 \\
Stomach & $-0.13^{*}$ & -0.39 \\
Head & $-0.24^{*}$ & -0.93 \\
Pectoral Muscle & 0.02 & -0.16 \\
Legs & 0.06 & $0.87^{*}$ \\
Wings & -0.02 & 0.10 \\
\hline
\end{tabular}

${ }^{1}$ Slope of regression has units $\% / g$ fresh egg weight. Probability that slope is not significantly different from zero. ${ }^{*} P<0.05,{ }^{* * P}<0.01$.

egg size, but the relationship between yolk size of the chick and egg size in the quail was not statistically significant (Table 3). Proportions of water, lipid, and nonlipid dry constituents also varied with respect to egg size in the gull (Table 5). The relative composition of the chick was expressed in terms of the water index (the ratio by weight of water to nonlipid dry matter) and lipid index (lipid/nonlipid dry matter). Water indices increased with egg size in both the gull and the quail (significantly only in the gull). Lipid indices decreased significantly in the gull and increased (but not significantly) in the quail. These systematic relationships between water index or lipid index and egg size were generally small compared to the total variation within the samples. In the relationship between the water index of the body and egg size in the gull, the slope of the regression $(0.077 / \mathrm{g})$ indicated a difference of 0.92 over the $12-\mathrm{g}$ range of egg weights in the sample; the total range in water index in the sample was 1.11 (5.04-3.93). The square of the correlation coefficient (coefficient of determination), indicating the proportion of variation in water index related to variation in egg weight, was 0.50 . Other coefficients of determination were smaller.

Variation in body proportion.-Table 6 shows correlations of the relative sizes of organs with variation in egg size. In the gull the relative weight of the integument increased as egg size increased, mainly owing to a disproportionate accumulation of water; the relative weights of the heart, head, and stomach decreased as egg size increased. The only significant correlation in body proportion of the quail was a marked increase in the size of the legs as egg size increased.

In the gull significant increases in the water index occurred in the integument, body carcass, pectoral muscle, legs, and wings. Significant decreases in the lipid index occurred in the liver and legs. The water and lipid indices of body components in the quail showed no significant changes.

\section{Discussion}

The relative proportions of lipid, water, and nonlipid dry matter in the egg of the Laughing Gull are essentially identical to those in the egg of the Japanese Quail. Linear regressions of the proportions of egg constituents on egg size (Table 2) indicated unvarying egg quality in the gull, but decrease in proportion of lipid and increase in proportion of nonlipid dry matter as a function of increasing egg size in the quail. In the domestic fowl the percentage of yolk in the egg also decreases slightly with increasing egg size even though the absolute size of the yolk increases 
TABLE 7

RELATIONSHIPS BETWEEN LOGARITHMS OF FRESH EgG WEIGHT AND LOGARITHMS OF COMPONENTS of Eggs and Chicks in the Laughing Gull and JaPanese QuaIL

\begin{tabular}{|c|c|c|c|c|}
\hline Component & Species & $\begin{array}{l}\text { Correlation } \\
\text { coefficient }\end{array}$ & Slope & $\begin{array}{c}\text { Standard } \\
\text { error of slope }\end{array}$ \\
\hline Egg lipid & $\begin{array}{l}\text { gull } \\
\text { quail }\end{array}$ & $\begin{array}{l}0.80 \\
0.70\end{array}$ & $\begin{array}{l}0.91 \\
0.73\end{array}$ & $\begin{array}{l}0.25 \\
0.21\end{array}$ \\
\hline Egg nonlipid dry matter & $\begin{array}{l}\text { gull } \\
\text { quail }\end{array}$ & $\begin{array}{l}0.93 \\
0.94\end{array}$ & $\begin{array}{l}0.97 \\
1.30\end{array}$ & $\begin{array}{l}0.14 \\
0.14\end{array}$ \\
\hline Egg water & $\begin{array}{l}\text { gull } \\
\text { quail }\end{array}$ & $\begin{array}{l}0.97 \\
0.89\end{array}$ & $\begin{array}{l}1.03 \\
0.98\end{array}$ & $\begin{array}{l}0.10 \\
0.14\end{array}$ \\
\hline Chick wet weight ${ }^{1}$ & $\begin{array}{l}\text { gull } \\
\text { quail }\end{array}$ & $\begin{array}{l}0.85 \\
0.83\end{array}$ & $\begin{array}{l}1.40 \\
1.18\end{array}$ & $\begin{array}{l}0.23 \\
0.33\end{array}$ \\
\hline Chick lipid $^{1}$ & $\begin{array}{l}\text { gull } \\
\text { quail }\end{array}$ & $\begin{array}{l}0.05 \\
0.73\end{array}$ & $\begin{array}{l}0.09 \\
1.59\end{array}$ & $\begin{array}{l}0.49 \\
0.60\end{array}$ \\
\hline Chick nonlipid ${ }^{1}$ dry matter & $\begin{array}{l}\text { gull } \\
\text { quail }\end{array}$ & $\begin{array}{l}0.87 \\
0.87\end{array}$ & $\begin{array}{l}1.00 \\
1.13\end{array}$ & $\begin{array}{l}0.15 \\
0.26\end{array}$ \\
\hline Chick water $^{1}$ & $\begin{array}{l}\text { gull } \\
\text { quail }\end{array}$ & $\begin{array}{l}0.81 \\
0.74\end{array}$ & $\begin{array}{l}1.61 \\
1.17\end{array}$ & $\begin{array}{l}0.30 \\
0.44\end{array}$ \\
\hline
\end{tabular}

${ }^{1}$ Including yolk in all chick components.

(Romanoff and Romanoff 1949). In the Starling (Sturnus vulgaris) the size of the yolk did not increase systematically with egg size in a sample of 12 eggs (Ricklefs 1977b), and although the level of nonlipid dry matter in the entire egg remained constant with varying egg size, the lipid level decreased with increased egg size. In the Herring Gull the slope of the relationship between yolk weight and egg weight $(0.15$, Parsons 1970) is about one-half the average proportion of yolk in the egg. The percentage yolk in the egg decreases as a function of increasing egg size from $30 \%$ in small eggs to $24 \%$ in large eggs (Parsons, pers. comm.). The slope of the relationship between total lipid and egg weight (0.09, Parsons 1970) is, however, similar to the average percentage of lipid in Laughing Gull eggs (9.7\%), indicating no change in proportion. It is difficult to compare changes in the proportions of constituents of bird eggs as a function of egg size in different species by linear regression statistics, because differences in average egg size and composition influence the slopes of such relationships. These difficulties can be avoided by regression statistics based on the logarithms of egg weight and component weight. As Lewontin (1966) pointed out, variances in logarithms can be compared directly by $F$-test. Furthermore the slope of the regression between the logarithm of a component and the logarithm of the whole indicates whether proportions undergo systematic changes with respect to egg size (slope different from 1). For example slopes of the logarithmic regressions of yolk weight on egg weight are $1.137 \pm 0.151$ (95\% confidence limits) for the Japanese Quail, $0.802 \pm 0.111$ for the Laughing Gull, and $0.314 \pm 0.182$ for the Starling. Thus in the quail yolk size increases in direct proportion to egg size (confidence limits of slope $(0.99-1.29)$ include 1.0$)$. The proportionate increase in the size of the yolk is significantly less in the gull, and it is very small in the Starling. Although the percent of yolk in the egg of the gull does not change significantly with variation in egg size (Table 2), the logarithmic regression shows that the proportion of yolk declines significantly as egg size increases (slope less than 1.0), as Parsons (pers. comm.) has shown for the Herring Gull. Thus, the Laughing Gull data support Parsons' (1972) contention that variation in egg size within the clutch is due largely to differences in 
TABLE 8

Comparison of the Slopes of Logarithmic Relationships of Egg and Chick Components to Egg Weight in the LaUghing Gull and JaPANeSE QuaIl

\begin{tabular}{lccrc}
\hline & \multicolumn{3}{c}{ Slope of relationship } \\
\cline { 2 - 4 } & $\begin{array}{c}\text { Wet } \\
\text { Weight }\end{array}$ & Water & $\begin{array}{c}\text { Nonlipid } \\
\text { dry matter }\end{array}$ & Lipid \\
\hline Laughing Gull & & & & \\
Egg & 1.00 & 1.03 & 0.97 & 0.91 \\
Chick $^{2}$ & 1.40 & 1.61 & 1.00 & 0.09 \\
Difference $^{3}$ & 0.40 & 0.57 & 0.03 & -0.82 \\
Japanese Quail & & & & \\
Egg $_{\text {Chick }}^{2}$ & 1.00 & 0.98 & 1.30 & 0.73 \\
Difference $^{3}$ & 1.18 & 1.17 & 1.13 & 1.59 \\
\hline
\end{tabular}

${ }^{1}$ Units for slopes are $\log g / \log g$ egg weight.

${ }^{2}$ Including yolk.

${ }^{3}$ Slope for chick minus slope for egg.

the amount of albumen secreted by the oviduct and not to variation in follicle development.

Gull and quail chicks are equally variable within a sample (Table 1). Similar amounts of this variation are linked to egg size in the gull and the quail; the correlation coefficients of chick weight and egg weight are 0.86 in the gull and 0.85 in the quail. These compare favorably with Parsons' (1970) value of 0.91 for the Herring Gull. Also the slope of the relationship between chick weight and egg weight in the quail $(0.79 \pm 0.20 \mathrm{SE})$ is similar to those of the Laughing Gull $(0.92 \pm 0.14 \mathrm{SE})$ and Herring Gull (0.75).

Although the proportionate composition and variation in the eggs of Japanese Quail and Laughing Gulls are similar, and the average composition of the chicks is similar, variation in egg size has markedly different consequences for variation in the chicks in the two species. The relationships between variation in the egg and variation in the chick are revealed by the slopes of logarithmic regressions between variables (Table 7). Although proportions of water, lipid, and nonlipid dry matter in the eggs of Laughing Gulls do not vary in relation to egg size (slopes of logarithmic regressions not significantly different from 1.0, Table 7), chick size and the proportion of water in the chick both increase out of proportion to egg size, while total lipid content of the chick is unrelated to egg size. Relative to the components of the egg, differential changes in the slopes of relationships between logarithms of chick and egg size are: wet weight +0.40 , water +0.57 , nonlipid dry matter +0.03 , and lipid -0.82 (Table 8).

In the quail the proportion of lipid in the egg decreases and the proportion of nonlipid dry matter in the egg increases as egg size increases (Table 7), but in the chick although wet weight, water, and nonlipid dry matter vary in direct proportion to egg size, lipid increases much more rapidly than egg size. Relative to the components of the egg, differential changes in the slopes of relationships between logarithms of chick and egg size are: wet weight +0.18 , water +0.19 , nonlipid dry matter -0.17 , and lipid +0.86 (Table 8 ).

Whatever advantages are conferred to the chick by increasing egg size must derive primarily by resulting in a general increase in body size in both the quail and gull, and from disproportionately large increases in water levels in the gull chick and lipid levels in the quail chick, as these were the consequences found. Large body size may 
confer advantage to chicks through enhanced ability to compete with sibs for food resources and brooding position, and through enhanced resistance to water loss and body temperature fluctuation. Large lipid reserves would be an obvious advantage to young, self-feeding quail chicks, which may not attain their full feeding skills until several days after hatching. Most laboratory-raised young lose weight for several days after hatching. The yolk and body lipid reserve of the young bird is depleted during this period (Romanoff 1944, Marcström 1960, Kear 1965, Ricklefs MS).

In the Laughing Gull the total lipid content of the chick is independent of egg size even though egg lipid varies in direct proportion to egg weight. Chicks from large eggs do, however, have a disproportionately high water content. Water storage could benefit chicks of species with invertebrate seafood in their diet because water is more difficult to extract from foods with high salt content than from most terrestrial foodstuffs, and fresh water is not available to seabird chicks. It also seems plausible that lipid is used as a source of water in the gull. Assuming a hydrogen content of lipid of $12 \%$ by weight (Brody 1945), the respiratory metabolism of lipid yields $0.96 \mathrm{~g}$ water for each gram of lipid metabolized. Storing lipid for eventual conversion to water is expensive energetically, but has the advantage that lipid will not evaporate from the egg.

Because large eggs have lower surface to volume ratios than small eggs, they lose water relatively less rapidly (Drent 1970). One may calculate the enhancement of water level in large eggs through differential evaporation rates using the expression: egg water (hatching) = egg water (laying) - water loss. Substituting egg water (laying) $=0.597 W^{1.031}($ Table 7$)$, water loss/day $=0.0151 W^{0.741}$ (Drent 1970), and an incubation period of 23 days (Oppenheim 1972), we find that over the range of egg weights from 35 to $50 \mathrm{~g}$, egg water (hatching) $=0.366 W^{\mathbf{1 . 1 0 3}}$, where $W$ is fresh egg weight. The slope of this relationship is much less than that observed (water $=0.049 \mathrm{~W}^{\mathbf{1 . 6 0 6}}$ ), indicating a major role of metabolically produced water. A similar calculation for the quail predicts the following relationship between egg water (hatching) and egg weight: water $=0.318 W^{1.108}$ The observed relationship is $0.338 W^{1.168}$.

Average lipid and water levels in newly hatched quail and gull chicks are nearly identical, in marked contrast to the different behavior of these constituents with respect to egg size in the two species. The significance of these differences in the relative utilization of water and lipid in the gull and quail could be viewed in the context of parental care and sibling competition. Young quail depend upon their parents only at an early age, and then for food location and brooding. As the selffeeding young grow, they become increasingly independent of parental care and as a result probably compete less with each other. Females apportion nutrients about equally among eggs in their clutch and the hatching of the young is highly synchronized.

In the gull competition among the young increases as the young grow and require more food. The size of the third egg in the clutch is noticeably smaller than the size of the first and second eggs, and the third egg produces an inferior chick with a lower survival rate than its larger sibs. The strategy of producing an inferior chick, either through manipulating egg size or hatching interval within the clutch is encountered commonly in birds as an adaptation to an uncertain food supply (Lack 1954, 1968, Ricklefs 1965). Differential egg size is an evolutionary strategy of the parent. Opposed to this behavior of producing an inferior chick, there must be selection on the chick itself to counteract the consequences of small egg size for its quality at hatching 
(Trivers 1974). Conservatism of lipid utilization may be one way in which this could be brought about. Even though chicks from small eggs have low body weights compared to sibs from larger eggs, their lipid reserves are as large, or larger when put on a per gram body weight basis. Parsons (1970) found a similar pattern when comparing chicks from first, second, and third-laid eggs in Herring Gulls, although total lipid in the chick varied in direct proportion to egg weight in the sample as a whole.

The physiological mechanisms by which gull embryos could conserve lipid reserves or, conversely, generate water through enhanced lipid metabolism, and the ability of the embryo to sense the size of the egg in which it is developing are beyond the scope of this study. Nonetheless, the contrast between utilization of egg nutrients by gulls and quail as a function of egg size indicate some interesting problems for future investigation.

In addition to relating variation in chicks to either the ecological requirements of the hatchling or competition between siblings, we may take a third view that differences between chicks merely represent differences in developmental stage at hatching. If chicks from large eggs differed from others only in being somewhat farther along the normal growth curve of the species, variation in body proportions and water levels in relation to chick size should parallel similar changes that occur with increasing age. This view certainly does not apply to the quail because young Coturnix do not gain weight during the first 4 days after hatching and at the time of hatching the weight of the stomach is increasing relatively faster than the weight of the legs (MS), in contrast to the change in proportions of these organs with increasing egg size. In the gull, however, chicks gain weight rapidly commencing immediately after hatching. Parsons (1972) has shown that the length of the incubation period increases as a function of egg size in comparisons involving several species of gulls and within Herring Gull populations. Although we have not analyzed the growth of gull chicks, one of the most striking changes in tern chicks immediately following hatching is a rapid increase in weight and water content of the integument (Ricklefs $1977 \mathrm{c}$ ). The relative sizes of the head and stomach are also decreasing at this time; these changes with respect to postnatal age are consistent with variation related to egg size (Table 6).

\section{ACKNOWLEDGMents}

We thank Malcolm Coulter, Erica Dunn, John M. Lawrence, and Jasper Parsons for commenting on an earlier draft of this paper. Susan Progoff assisted in the laboratory analyses. The study was supported in part by NSF GB 42661 (R.E.R.).

\section{Literature Cited}

Behle, W. H., AND W. A. Goates. 1957. Breeding biology of the California Gull. Condor 59: 235-246. Brody, S. 1945. Bioenergetics and growth. New York, Reinhold.

Coulson, J. C. 1963. Egg size and shape in the Kittiwake (Rissa tridactyla) and their use in estimating age composition of populations. Proc. Zool. Soc. London 140: 211-227.

Davis, J. W. F. 1975. Age, egg-size and breeding success in the Herring Gull Larus argentatus. Ibis 117: $460-473$.

Drent, R. H. 1970. Functional aspects of incubation in the Herring Gull (Larus argentatus Pont.). Behaviour, Suppl. 17: 1-132.

Halbersleben, D. L., ANd F. E. Mussehl. 1922. The relation of egg weight to chick weight at hatching. Poultry Sci. 1: 143-144. 
HARRIS, M. P. 1964. Aspects of the breeding biology of the gulls Lamus argentatus, fuscus, marinus. Ibis 106: $432-456$.

KEAR, J. 1965. The internal food reserves of hatching Mallard ducklings. J. Wildl. Mgmt. 29: 523-528.

$\rightarrow$ Kendeigh, S. C., T. C. Kramer, AND F. HAMerstrom. 1956. Variation in egg characteristics of the House Wren. Auk 73: 42-65.

LACK, D. 1954. The natural regulation of animal numbers. London, Oxford University Press.

- 1968. Ecological adaptations for breeding in birds. London, Methuen.

Lewontin, R. C. 1966. On the measurement of relative variability. Syst. Zool. 14: 141-142.

MARCSTRöM, V. 1960. Studies on the physiological and ecological background to the reproduction of the Capercaillie (Tetrao urogallus Linn.). Viltrevy 2: 1-69.

Nisbet, I. C. T. 1973. Courtship feeding, egg-size and breeding success in Common Terns. Nature 241: 141-142.

Oppenheim, R. W. 1972. Prehatching and hatching behaviour in birds: A comparative study of altricial and precocial species. Anim. Behav. 20: 644-655.

Paludan, K. 1951. Contributions to the breeding biology of Larus argentatus and Larus fuscus. Dansk. Nat. Hist. Foren., Vidensk. medd. 144: 1-128.

PARSONS, J. 1970. Relationship between egg size and post-hatching chick mortality in the Herring Gull (Larus argentatus). Nature 228: 1221-1222.

—. 1972. Egg size; laying date and incubation period in the Herring Gull. Ibis 114: 536-541.

Preston, F. W., ANd E. J. Preston. 1953. Variation of the shapes of birds' eggs within the clutch. Ann. Carnegie Mus. 33: 128-139.

Ricklefs, R. E. 1965. Brood reduction in the Curve-billed Thrasher. Condor 67: 505-510.

-. 1974. Energetics of reproduction in birds. Pp. 152-292 in Avian Energetics (R. A. Paynter, Ed.). Publ. Nuttall Ornithol. Club, No. 15.

- 1975. Patterns of growth in birds, part 3, Growth and development of the Cactus Wren. Condor 77: $34-45$.

$\longrightarrow$ 1977a. The composition of eggs of several bird species. Auk 94: 350-356.

$\longrightarrow 1977 \mathrm{~b}$. Variation in the size and quality of the Starling egg. Auk 94: 167-168.

- 1977c. Patterns of growth in birds, part 5, A comparative study of development in the Starling, Common Tern, and Japanese Quail. Auk. In press.

$\rightarrow$ Romanoff, A. L. 1944. Avian spare yolk and its assimilation. Auk 61: 235-241.

— AND A. J. Romanoff. 1949. The avian egg. New York, Wiley.

SCHIFFERLI, L. 1973. The effect of egg weight on the subsequent growth of nestling Great Tits Parus major. Ibis 115: 549-558.

Skogland, W. C., K. C. Seegar, and A. T. Ringrose. 1952. Growth of broiler chicks hatched from various sized eggs when reared in competition with each other. Poultry Sci. 31: 796-799.

Trivers, R. L. 1974. Parent-offspring conflict. Amer. Zool. 14: 249-264.

UPP, C. W. 1928. Egg weight, day old chick weight, and rate of growth in Single Comb Rhode Island Red chicks. Poultry Sci. 7: 151-155.

Warham, J. 1974. The Fiordland Crested Penguin Eudyptes pachyrhynchus. Ibis 116: 1-27.

Wiley, W. H. 1950. The influence of egg weight on the pre-hatching and post-hatching growth rate in the fowl. Poultry Sci. 29: 570-574. 